\title{
Two Independent Frontal Midline Theta Oscillations during Conflict Detection and Adaptation in a Simon-Type Manual Reaching Task
}

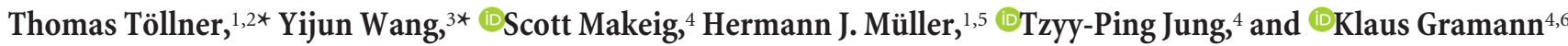 \\ ${ }^{1}$ Department of Experimental Psychology and ${ }^{2}$ Graduate School of Systemic Neurosciences, LMU Munich, D-80802 Munich, Germany, ${ }^{3}$ State Key \\ Laboratory on Integrated Optoelectronics, Institute of Semiconductors, Chinese Academy of Sciences, Beijing 100083, China, ${ }^{4}$ Swartz Center for \\ Computational Neuroscience, Institute for Neural Computation, University of California, San Diego, La Jolla, California 92093, ${ }^{5}$ Department of \\ Psychological Sciences, Birkbeck College, University of London, London, WC1E 7HX, United Kingdom, and ${ }^{\circ}$ Department of Biological Psychology and \\ Neuroergonomics, TU Berlin, D-10587 Berlin, Germany
}

One of the most firmly established factors determining the speed of human behavioral responses toward action-critical stimuli is the spatial correspondence between the stimulus and response locations. If both locations match, the time taken for response production is markedly reduced relative to when they mismatch, a phenomenon called the Simon effect. While there is a consensus that this stimulusresponse $(\mathrm{S}-\mathrm{R})$ conflict is associated with brief $(4-7 \mathrm{~Hz})$ frontal midline theta $(\mathrm{fm} \theta)$ complexes generated in medial frontal cortex, it remains controversial (1) whether there are multiple, simultaneously active theta generator areas in the medial frontal cortex that commonly give rise to conflict-related $\mathrm{fm} \theta$ complexes; and if so, (2) whether they are all related to the resolution of conflicting task information. Here, we combined mental chronometry with high-density electroencephalographic measures during a Simon-type manual reaching task and used independent component analysis and time-frequency domain statistics on source-level activities to model fm $\theta$ sources. During target processing, our results revealed two independent fm $\theta$ generators simultaneously active in or near anterior cingulate cortex, only one of them reflecting the correspondence between current and previous S-R locations. However, this fm $\theta$ response is not exclusively linked to conflict but also to other, conflict-independent processes associated with response slowing. These results paint a detailed picture regarding the oscillatory correlates of conflict processing in Simon tasks, and challenge the prevalent notion that fm $\theta$ complexes induced by conflicting task information represent a unitary phenomenon related to cognitive control, which governs conflict processing across various types of response-override tasks.

Key words: cognitive control; conflict processing; independent component analysis

Significance Statement

Humans constantly monitor their environment for and adjust their cognitive control settings in response to conflicts, an ability that arguably paves the way for survival in ever-changing situations. Anterior cingulate-generated frontal midline theta (fm $\theta$ ) complexes have been hypothesized to play a role in this conflict-monitoring function. However, it remains a point of contention whether fm $\theta$ complexes govern conflict processing in a unitary, paradigm-nonspecific manner. Here, we identified two independent $\operatorname{fm} \theta$ oscillations triggered during a Simon-type task, only one of them reflecting current and previous conflicts. Importantly, this signal differed in various respects (cortical origin, intertrial history) from fm $\theta$ phenomena in other response-override tasks, challenging the prevalent notion of conflict-induced $\mathrm{fm} \theta$ as a unitary phenomenon associated with the resolution of conflict.

\section{Introduction}

It is well established that human behavioral responses are slower when the appearance of a response-imperative stimulus is spa- tially incongruent with its associated response (e.g., a left stimulus prompting a right-hand, rather than a left-hand, response). This reaction time (RT) difference, often referred to as "Simon 


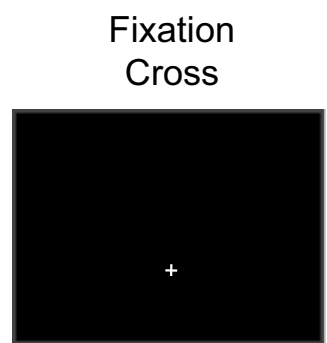

$500 \mathrm{~ms}$

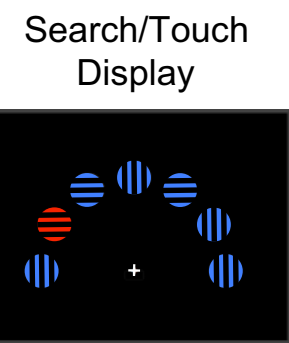

$200 \mathrm{~ms}$

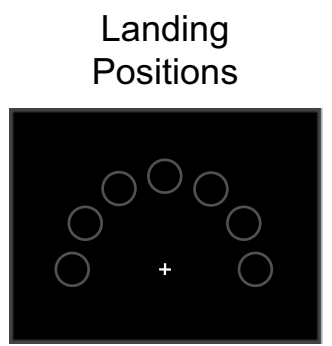

until response

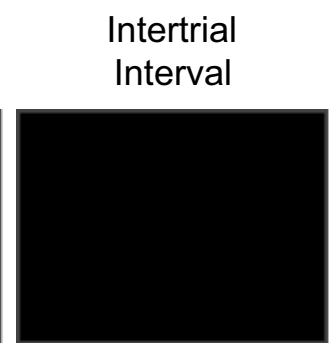

$1000 \pm 50 \mathrm{~ms}$

Figure 1. Sample trial sequence in the present Simon-type manual reaching task. The target was randomly defined by color (red) or shape (square), with the correct motor response (left vs right hand) being defined, independently of the target-defining attribute (color vs shape), by the orientation of the stripes inside the target (vertical vs horizontal). Target positions were selected randomly, on a trial-by-trial basis, from all but the central and the two outer positions.

effect" (Simon and Small, 1969), is independent of the sensory modality of the stimulus and depends on the spatial location of the motor action rather than the actual effector (e.g., left vs right hand) with which the action is executed (Simon, 1969; Wallace, 1971). Thus, theoretical accounts (Umiltà and Nicoletti, 1992; Hommel et al., 2004) generally agree that the Simon effect is driven by the conflict between representations that code the stimulus and, respectively, response locations. The degree of this conflict-related slowing is further determined by the recent history of spatial conflict (Gratton et al., 1992; Mayr et al., 2003; Ullsperger et al., 2005; Egner, 2007): incongruent responses are faster on a given trial when the preceding response was also incongruent. This "conflict-adaptation effect" (also referred to as "Gratton effect") suggests that encountering a conflict gives rise to an adjustment of internal system settings such that performance is facilitated on a subsequent conflict trial (Gratton et al., 1992; Ridderinkhof et al., 2004; Töllner et al., 2012a).

At the level of brain dynamics, there is mounting evidence that at least two frontal brain regions are involved in behavioral adjustments following a response conflict in the Simon task. Kerns (2006) showed that conflict-related hemodynamic activity in anterior cingulate cortex (ACC) is related to increased prefrontal cortex (PFC) activity, which, in turn, is associated with improved behavioral responses on the next trial. Following the conflictmonitoring hypothesis (Botvinick et al., 2004), Kerns (2006) suggested that the ACC becomes activated whenever a conflict is detected, and this activation is then projected to other brain areas (including the PFC) involved in the proactive minimization of potential conflicts on subsequent trials.

Complementing these hemodynamic findings, recent electroencephalographic (EEG) investigations have provided insights into the spectrotemporal brain dynamics that mediate conflict detection and adaptation in the classic Simon task (Cohen and Ridderinkhof, 2013; Gulbinaite et al., 2014) as well as in (cueing) variants of this task (Cavanagh et al., 2012; van Driel et al., 2015; Mückschel et al., 2016). The emerging picture suggests that the noncorrespondence between stimulus (S) and response (R) locations is associated with brief medial frontal cortex (MFC)-generated theta complexes. In more detail, trials with incongruent $\mathrm{S}-\mathrm{R}$ locations give rise to stronger frontal midline theta $(\operatorname{fm} \theta)$ complexes than trials with congruent locations (Cavanagh et al., 2012), with conflict-induced $\operatorname{fm} \theta$ complexes being reduced when participants had processed a conflict on the preceding

Correspondence should be addressed to Dr. Thomas Töllner, Department of Experimental Psychology and Graduate School of Systemic Neurosciences, LMU Munich, Leopoldstrasse 13, D-80802 Munich, Germany. E-mail: thomas.toellner@psy.Imu.de.

DOI:10.1523/JNEUROSCI.1752-16.2017

Copyright $\odot 2017$ the authors $\quad 0270-6474 / 17 / 372505-12 \$ 15.00 / 0$ trial (Cohen and Ridderinkhof, 2013). These and other findings led to the prominent proposal that such $\operatorname{fm} \theta$ complexes are associated with a brain process that mediates conflict processing (Nigbur et al., 2011). At variance with this view, others have argued that conflictrelated theta modulations, rather than reflecting processing of conflict per se, are attributable to more general "time-on-task" processes (Scherbaum and Dshemuchadse, 2013). That is, the changes in the oscillatory EEG pattern may simply reflect changes in RT performance.

The present study was designed to provide a more detailed picture as to (1) whether there are multiple, concurrently active theta generators in the MFC, and if so, (2) whether they are all related to S-R conflict. For example, it is conceivable that separable $\operatorname{fm} \theta$-associated processes (e.g., conflict detection, adaptation, conflict-unrelated processes) arise from functionally and physiologically distinct theta activities, not easily detectable by conventional analyses of scalp channel signals. Alternatively, different conflict-related and -unrelated processes may drive one-and-thesame $\operatorname{fm} \theta$ complex. To decide between these alternatives, we recorded high-density EEG during a Simon-type manual reaching task and used independent component analysis (ICA) (Makeig et al., 1996) to decompose statistically independent source processes whose spatial origins could then be studied using equivalent dipole modeling (Makeig et al., 2002).

\section{Materials and Methods}

Participants. Fourteen healthy adults recruited from the University of California San Diego took part in this study; data from two participants had to be excluded because of excessive artifacts during EEG acquisition. The remaining 12 participants were between 20 and 30 (median 25) years of age; by chance, 10 were male. They had all normal or corrected-tonormal vision, and none reported a history of neurological disorders. Each participant provided written informed consent before the start of the experiment. All experimental procedures were approved by the local Institutional Review Board in accord with the Code of Ethics of the World Medical Association (Declaration of Helsinki).

Stimulus, task, and study design. Visual displays consisted of seven colored shapes on a black background, which were arranged regularly on a semicircle around a (central) white fixation cross at the screen bottom; the stimulus eccentricity was $6.0^{\circ}$ of visual angle (Fig. 1). On each trial, a feature singleton target, randomly defined by color (red circles; CIE $0.213,0.264,68$; radius: $2.4^{\circ}$ ) or shape (blue squares; CIE $0.389,0.518,68$; $\left.4.8^{\circ} \times 4.8^{\circ}\right)$, was presented together with six homogeneous distractor items (blue circles; CIE $0.389,0.518,68$; radius: $2.4^{\circ}$ ). The position of the target was selected randomly from all but the central (top) and the two outer (left- and right-most) positions. Each stimulus outline contained a grating composed of three black bars $\left(0.8^{\circ} \times 4.8^{\circ}\right)$ separated by two gaps $\left(0.6^{\circ} \times 4.8^{\circ}\right)$, randomly oriented either vertically or horizontally.

Participants were seated comfortable in a dimly lit, sound-attenuated experimental booth. Visual displays were presented on a 21 -inch com- 
puter touch screen monitor. Each experimental session consisted of 20 blocks of 60 trials each, yielding a total of 1200 trials. A trial started with a white central fixation cross displayed for $0.5 \mathrm{~s}$, followed by the stimulus display presented for $0.2 \mathrm{~s}$. Next, all stimuli were masked by "placeholders" (Fig. 1) until the participant's response or for a maximum period of $0.8 \mathrm{~s}$. In case of a response error or if no response was issued within the maximum allowed RT window ( $1 \mathrm{~s})$, the word "ERROR" was presented centrally for $1 \mathrm{~s}$. In the interval to the next trial, participants were presented with a central white fixation cross for a randomly chosen duration of $0.95,1$, or $1.05 \mathrm{~s}$. To initiate the trial, they had to press two customized keypad buttons mounted centrally on the lower frame of the touchscreen using both index fingers.

Participants were asked to maintain central eye fixation throughout all blocks and to perform, as fast and as accurately as possible, a visually guided manual reaching action. To dissociate perceptual from motor response selection for the planned intertrial analyses, we used a compound-search design (Töllner et al., 2008, 2012b): participants had first to detect and localize the target (defined by a unique color or shape) before they could extract the information (the target's vertical vs horizontal stripe orientation) that specified the required motor action: touching the target (location) on the (touch) screen using either their left- or their right-hand index finger, depending on the stripe orientation. Half the participants started to respond to vertical orientation with their left and to horizontal orientation with their right hand, and vice versa for the other half (the S-R mapping was reversed halfway through the experiment). We used vertical versus horizontal orientation as response-critical attributes as these do not convey any lateralized information that might have confounded the Simon effect (Hommel, 2011). To start a trial, participants had to (re)position both index fingers on the keypad buttons (i.e., the starting positions), and trials were immediately aborted and counted as errors if both keypad buttons (rather than just one) were released during a trial. Before the start of the experiment, one block of practice ( 60 trials) was administered to familiarize participants with the S-R mapping (e.g., vertical/horizontal target orientation demanding a left-/right-hand response). After each block, participants received summary statistics feedback (mean RT and error rate).

Electroencephalographic recording and analysis. The EEG was digitized continuously at $512 \mathrm{~Hz}$ using a 248-channel active electrode array (Active II, Biosemi). Electrodes were mounted on an elastic cap, with exact locations measured individually using a 3-D ultrasound digitizer system (Polhemus). Electrode impedances were kept $<20 \mathrm{k} \Omega$. All offline EEG analyses were based on custom MATLAB (The MathWorks) scripts, built on the open source EEGLAB toolbox (Delorme and Makeig, 2004). To start with, we inspected all raw data visually to identify and manually remove nonstereotypical noise. Next, we rejected all channels exhibiting excessive artifacts, defined as any signal exceeding $\pm 1 \mathrm{mV}$, and channels with kurtosis $>5$ SDs from the mean kurtosis across all channels. The EEG data were then high-pass filtered $(0.1 \mathrm{~Hz})$, rereferenced to average reference, and decomposed into temporally maximally independent source processes using adaptive mixture independent component analysis (Palmer et al., 2006, 2008; Delorme et al., 2012), which generalizes previously established infomax (Bell and Sejnowski, 1995; Makeig et al., 1996) and multiple mixture ICA approaches (Lee et al., 1999; Lewicki and Sejnowski, 2000), to dissociate scalp-recorded EEG signals into spatially static components that are statistically maximally independent. Of importance for the question at issue in the current study, ICA does not only dissociate brain from nonbrain sources, but also other activities projecting to the scalp from multiple brain sources.

Electrocortical source analysis. For each of the independent component (IC) scalp topographies, a single-equivalent current dipole model was computed using a boundary element head model (Fuchs et al., 2002; Oostenveld and Oostendorp, 2002) as implemented in the DIPFIT plug-in of the EEGLAB toolbox. Coregistration of the electrode positions with the MNI brain template (representing an average MRI scan from 152 healthy adults; available at http://www.mni.mcgill.ca) was performed by aligning particular landmarks (nasion, inion, ears, and vertex) and, if required, rescaling and/or rotating the montage setting. Next, we selected ICs for further analysis only if their equivalent current dipoles were located within cortical gray matter; restated, we excluded all ICs with dipoles localized outside the brain (including those accounting for eye movement or muscle activity). In addition, we rejected any ICs from further analyses whose equivalent dipole model accounted for $<85 \%$ of the variance of the IC scalp map (e.g., ICs with multifocal scalp maps not compatible with generation in a single cortical region).

IC clustering and statistics. Following ICA decomposition, the EEG data were epoched into $3 \mathrm{~s}$ segments, ranging from $1 \mathrm{~s}$ before to $2 \mathrm{~s}$ after stimulus onset. All remaining ICs were then clustered across all participants based on their spatial projections and measures of their eventrelated brain dynamics (Delorme and Makeig, 2004; Gramann et al., 2010), including their equivalent dipole locations, scalp maps, mean log spectra, event-related potentials, intertrial coherences, and event-related spectral perturbations (ERSPs) (Makeig, 1993), applying a $k$-means approach. ICs $>3$ SDs distant from the cluster centroid were removed from each cluster. We then inspected all clusters to identify IC sets with a cluster mean scalp topography exhibiting a weight distribution with a maximum over $\operatorname{fm} \theta$ areas (for theta band analysis, compare Ishii et al., 1999; Buzsaki, 2006; Cohen et al., 2008).

ERSPs, our main measure of interest (see below), were computed by transforming each IC time series into a spectrographic image. Frequency-specific event-related changes in spectral power were calculated across the frequency range of 3-128 Hz using Morlet wavelet decomposition (as implemented in EEGLAB). Specifically, we used 3-cycle Morlet wavelets for the lowest frequency $(3 \mathrm{~Hz})$ and linearly increased the cycle number (per wavelet) to 25.6 cycle Morlet wavelets for the highest frequency $(128 \mathrm{~Hz})$ to balance the frequency/temporalresolution trade-off. Spectrographic images for each trial were then averaged and converted to log power. Log power at each frequency in the prestimulus baseline period ( $-1 \mathrm{~s}$ to stimulus onset) was subtracted from the log spectrogram.

To statistically analyze both conflict detection and adaptation effects, all (left- and right-hand response), trials were first separated into "congruent" (i.e., left/right stimulus location requiring left/right motor action) and "incongruent" trial types (i.e., left/right stimulus location requiring right/left motor action). These two conditions were then further split as a function of previous, "congruent" versus "incongruent," trial history, resulting in four experimental conditions (congruent-congruent, incongruent-congruent, congruent-incongruent, incongruent-incongruent). All behavioral (RTs) and neural measures (ERSPs) were analyzed using separate repeatedmeasures ANOVAs with the factors "Current S-R congruency" (congruent, incongruent) and "Previous S-R congruency" (congruent, incongruent). Significant main effects and/or interactions were further verified by means of post hoc comparisons (two-tailed paired $t$ tests). For spectrotemporal analyses, theta-band (4-7 Hz) ERSP values were extracted and analyzed for both stimulus-locked segments (from $0.5 \mathrm{~s}$ before to $1 \mathrm{~s}$ after stimulus onset) and response-locked segments (from $1 \mathrm{~s}$ before to $0.5 \mathrm{~s}$ after response onset) on the component cluster level.

\section{Results}

\section{Behavioral data}

Replicating the classical Simon task literature, RTs were robustly modulated by spatial S-R compatibility (Fig. $2 \mathrm{~A}$, top): participants responded slower when the side of the motor action was spatially incongruent, compared with congruent, with the side on which the target stimulus was presented (653.22 $\pm 42.06 \mathrm{~ms}$ vs $615.63 \pm 48.93 \mathrm{~ms}, p<0.001)$. Importantly, the S-R compatibility effect interacted with the S-R compatibility on the previous trial $\left(F_{(1,13)}=165.25, p<0.001\right)$ : responses were produced faster on incongruent trials $(642.39 \pm 42.03 \mathrm{~ms}$ vs $665.61 \pm 42.92 \mathrm{~ms})$ and slower on congruent trials (625.99 $\pm 48.54 \mathrm{~ms}$ vs $607.09 \pm$ $49.25 \mathrm{~ms}$ ) if participants had previously responded to an incongruent target (Fig. 2A, bottom). As further depicted in Figure $2 \mathrm{~A}$, the general RT pattern was the same when calculating left- and right-hand responses separately. Participants exhibited slightly more error-prone behavior on congruent $(6.90 \pm 1.88 \%$ vs $6.14 \pm 1.73 \%)$ and incongruent trials $(6.46 \pm 1.31 \%$ vs $6.16 \pm$ $2.21 \%$ ) when there was an S-R incompatibility on the previous 
A

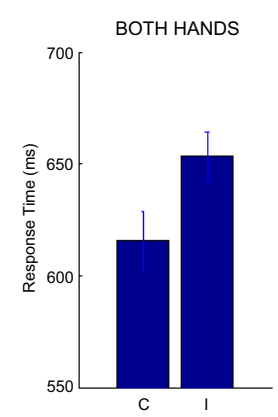

Reaction Times
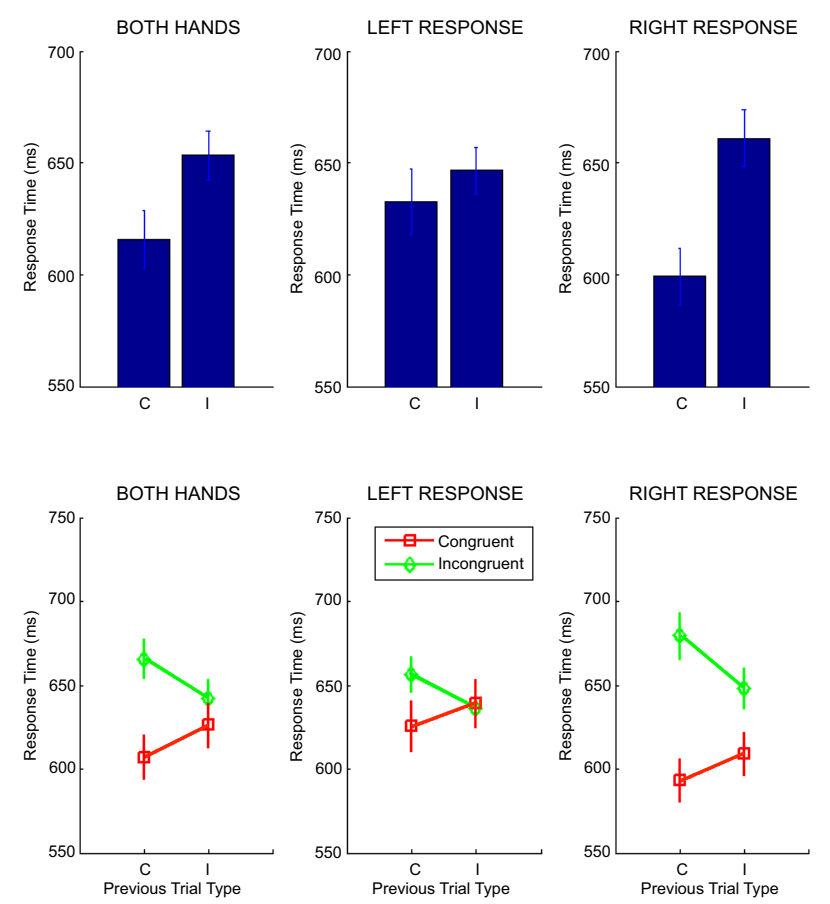

B
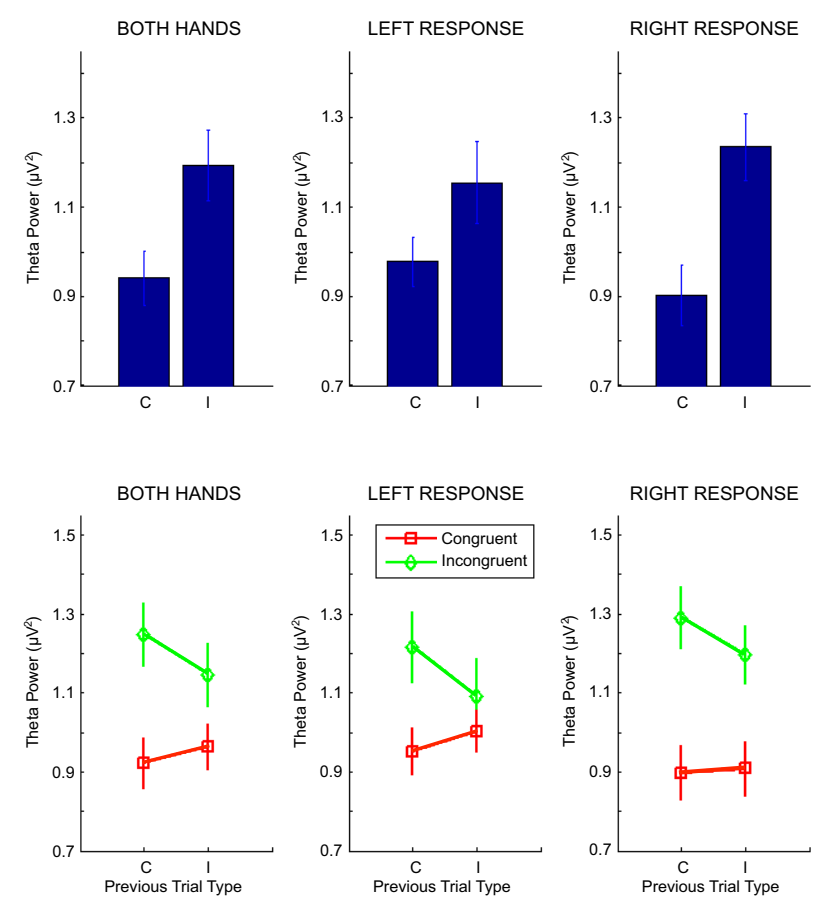

Figure 2. Conflict-related behavioral and neural responses averaged across hands, separately for left-hand and right-hand responses. $\boldsymbol{A}$, Top, Differences in RTs between congruent (C; no-conflict) and incongruent (l; conflict) trials. Bottom, RTs separately for congruent (red lines) and incongruent trials (green lines) as a function of the S-R compatibility on the previous trial. $\boldsymbol{B}$, Top, Differences in MFC theta activations between congruent (no-conflict) and incongruent (conflict) trials. Bottom, MFC theta activations separately for congruent (red lines) and incongruent trials (green lines) as a function of the previous $S-R$ compatibility.

trial. However, none of the error-related differences reached statistical significance (all $p$ values $>0.18$ ).

\section{Frontal midline IC clusters}

In line with the central question at issue, and for the sake of brevity, we present results only for those IC clusters whose centroids were located within cortical gray matter and whose mean scalp topography exhibited a weight distribution maximal over frontal midline scalp areas (from which $\operatorname{fm} \theta$ effects are typically measured). Two clusters with centroids located in or near dorsal ACC fulfilled these criteria. These clusters showed functionally distinct EEG dynamics under different experimental conditions: the first cluster comprised ICs from eight participants whose model equivalent dipoles were located in or near medial prefrontal cortex (MPFC); the second cluster comprised ICs from 10 participants localized in or near the MFC. Scalp projections of the ICs in each cluster are depicted in Figure $3 A$. As can be seen from Figure $3 B$, equivalent dipoles for ICs in the two theta clusters show distinctive distributions in MPFC and MFC areas, respectively.

\section{Frontal midline theta activity and conflict detection}

Figure $3 C$ presents the spectrographic ERSP images for both the MPFC (left panel) and MFC (right panel) IC clusters synchronized to the onset of the stimulus. ERSP analyses revealed that both $\operatorname{fm} \theta$ clusters produced clearly distinguishable brief enhancements in mean theta power $(4-7 \mathrm{~Hz})$ for both congruent and incongruent $\mathrm{S}-\mathrm{R}$ conditions. In addition to the theta burst, the MPFC cluster selectively exhibited an event-related synchronization in the low beta frequency band $(12-15 \mathrm{~Hz})$, whereas the MFC cluster selectively exhibited an event-related desynchroni- zation in the mid-beta band $(20-24 \mathrm{~Hz})$. Most importantly, however, incompatibility between the $\mathrm{S}$ and $\mathrm{R}$ sides (i.e., the $\mathrm{S}-\mathrm{R}$ conflict) was exclusively accompanied by event-related theta band activity changes in the MFC cluster. That is, when subtracting the congruent from the incongruent S-R condition, the only difference that remained was theta band activity in the MFC cluster (Fig. 3C). This observation was statistically substantiated by stronger MFC theta bursts in the incongruent compared with the congruent S-R conditions $\left(1.19 \pm 0.25 \mu \mathrm{V}^{2}\right.$ vs $0.94 \pm 0.19 \mu \mathrm{V}^{2}$; $p<0.01$; see also Fig. $2 B$, top), in line with the notion that heightened conflict processing goes along with stronger MFC activity (e.g., Kerns, 2006). The theta burst in the MPFC cluster, the beta event-related synchronization in the MPFC cluster, as well as the beta event-related desynchronization in the MFC cluster, by contrast, occurred independently of S-R conflict, that is, there were no significant differences between congruent and incongruent conditions (all $p$ values $>0.14$ ).

\section{MFC theta activity and conflict adaptation}

In the next step, we analyzed the theta band activity in the conflict-dependent MFC cluster as a function of preceding, congruent versus incongruent, trial history. This analysis revealed the theta band activity on the current trial being modulated by the $\mathrm{S}-\mathrm{R}$ compatibility on the previous trial (Fig. 2B, bottom). Theta bursts triggered on incongruent trials were significantly reduced when participants had processed an incongruent, rather than a congruent, S-R condition in the preceding trial episode (1.14 \pm $0.25 \mu \mathrm{V}^{2}$ vs $\left.1.24 \pm 0.25 \mu \mathrm{V}^{2} ; p<0.01\right)$. By contrast, theta bursts on congruent trials were significantly enhanced when participants had processed an S-R conflict on the previous trial (0.96 \pm 
A
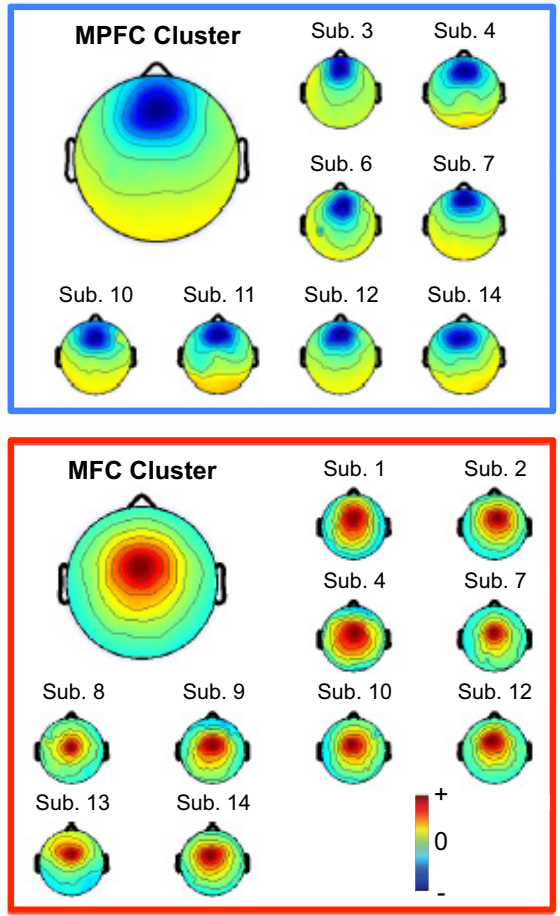

B

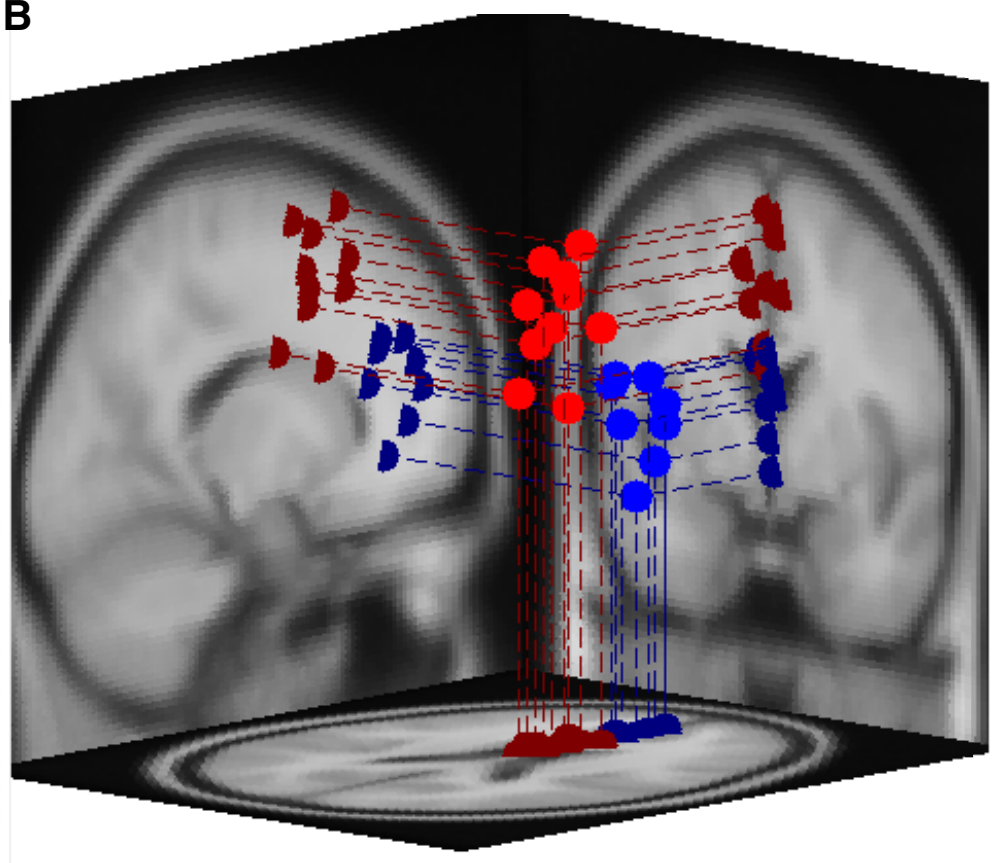

C

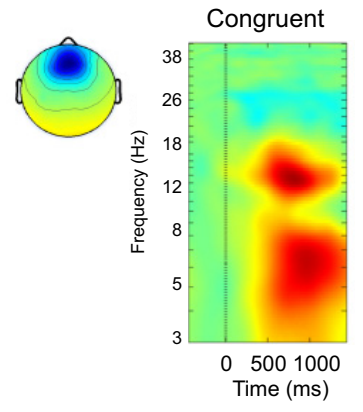

Incongruent $\mathrm{dB}$

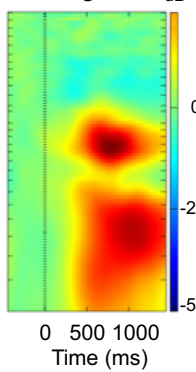

Difference

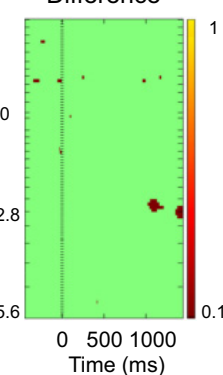

Congruent
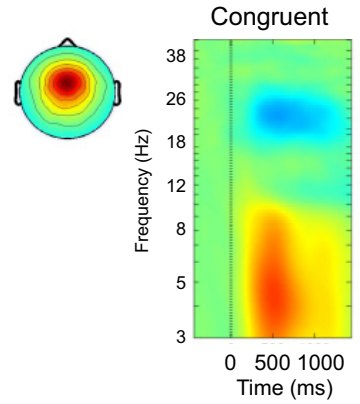

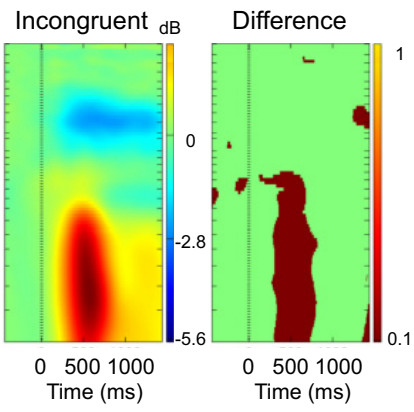

Figure 3. Two clusters of ICEEG source processes with equivalent dipole centroids in or near ACC. A, Larger maps, Mean scalp topographies for the MPFC (top) and MFC (bottom) IC Clusters. Smaller maps, Topographies of their individual ICs. Map sign orientation (red vs blue) is arbitrary. B, Equivalent dipole locations of individual ICs in the MPFC (blue spheres, lines) and MFC (red spheres, lines) IC clusters projected on horizontal, sagittal, and coronal views of the standard MNI template brain. Cluster centroids of the equivalent dipole locations (data not shown) are as follows: MPFC, BA32, Talairach coordinates, $x=1, y=38, z=11$ (blue); MFC, BA32, Talairach coordinates, $x=0, y=9, z=39$ (red). C, Cluster-mean event-related spectral perturbations time-locked to onset of stimuli mandating spatially congruent and incongruent responses, respectively, for the MPFC (left) and MFC (right) IC clusters. Dark red represents significant ( $p<0.01$ by two-tailed paired $t$ tests) inincongruent-minus-congruent ERSP differences between the two conditions. Note the absence of an $\mathrm{fm} \theta$ difference for the MPFC cluster.

$0.18 \mu \mathrm{V}^{2}$ vs $\left.0.92 \pm 0.19 \mu \mathrm{V}^{2} ; p<0.01\right)$. As with the RT data, essentially the same interactive pattern was evident when plotting the MFC theta power separately for left- and right-hand responses (Fig. 2B, bottom). This set of findings is in line with the notion that, after having encountered conflict, humans reactively adjust their internal system settings to proactively prevent, or minimize, the costs associated with conflicts that potentially occur on subsequent trials (Botvinick et al., 2004; Kerns, 2006).

\section{Dissociating conflict processing from general RT-related slowing in MFC theta power}

However, one common difficulty in using RT paradigms to study EEG oscillations is that any change in the oscillatory pattern may be a direct correlate of a concurrent RT change. Applied to the present data, this implies that the increase in theta power for incongruent relative to congruent trials may not reflect the conflict between internal representations that code spatial S-R locations, respectively, but rather more general RT slowing or time-on-task processes (Scherbaum and Dshemuchadse, 2013). In other words, it remains unclear at this stage whether the MFC theta bursts in the present Simon-type task are due to (1) the conflict between S-R locations, (2) more general processing demands associated with RT slowing, or (3) a mixture of both. If MFC theta bursts reflect exclusively the S-R conflict, we should observe MFC theta being triggered more markedly for incongruent relative to congruent trials, without any RT modulation (Fig. 4, first panel). By contrast, if the MFC theta increase reflects exclusively RT-related processing demands, MFC theta power should increase gradually as RT increases, without any modulation by S-R compatibility (Fig. 4, second panel). If the MFC theta increase reflects both effects, however, we should observe MFC theta power being triggered more strongly for incongruent relative to congruent trials, with further increases in trials with slow RTs. In the latter case, two scenarios are conceivable: The RTrelated increase in MFC theta across different $\mathrm{RT}$ ranges (i.e., quartiles) may be comparable between congruent and incongru- 


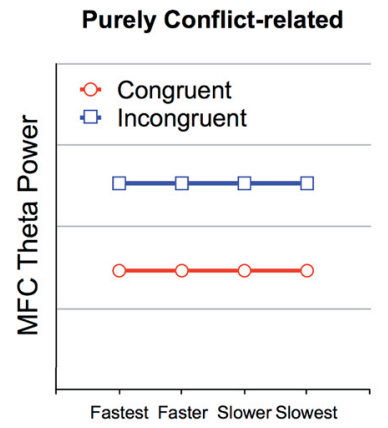

RT Quartiles

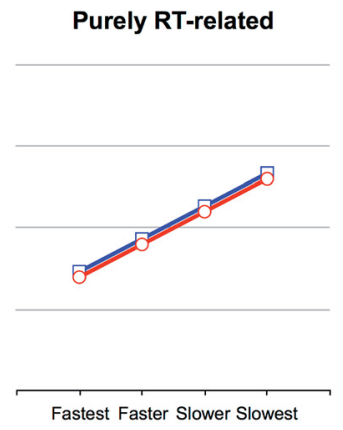

RT Quartiles

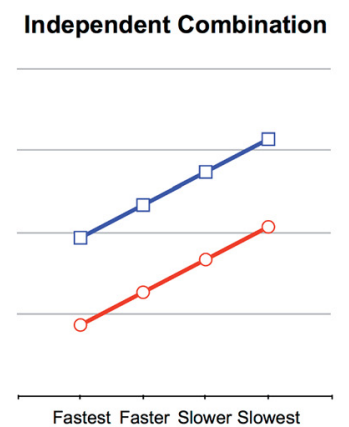

RT Quartiles
Interactive Combination

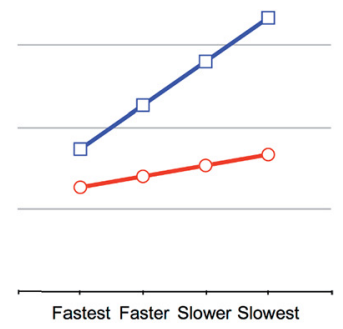

RT Quartiles

Figure 4. Hypothetical data patterns for MFC theta power. Left panels, Predicted MFC theta increases produced by a pure conflict-related versus a pure RT-related modulation. Right panels, Predicted MFC theta increases produced by a combination of both conflict- and RT-related modulations, determining MFC theta power either independently of one another or interactively. In all hypothetical scenarios, each RT quartile is assumed to correspond to the same bounds for congruent (red lines) and incongruent trials (blue lines).

ent trials, which would point to an independent modulation of conflict- and RT-related processes (Fig. 4, third panel). Alternatively, the slopes may differ between congruent and incongruent trials (e.g., steeper for incongruent trials), which would indicate that conflict- and RT-related processes determine MFC theta power interactively (Fig. 4, fourth panel).

To directly test these four alternatives, we sorted the stimuluslocked MFC theta power time courses in all trials by RT for each participant individually (Fig. 5C) and split the trials into four subsets representing different levels of response speed: fastest (mean RT: $526 \mathrm{~ms}$ ), faster (mean RT: $593 \mathrm{~ms}$ ), slower (mean RT: $650 \mathrm{~ms}$ ), and slowest (mean RT: $733 \mathrm{~ms}$ ). Each subset consisted of comparable numbers of trials (fastest: $221 \pm 32$; faster: $221 \pm 22$; slower: $225 \pm 32$; slowest: $224 \pm 31$; see Fig. $5 D$ ), with RT quartiles being computed across congruency conditions (i.e., each RT quartile corresponds to the same bounds for congruent and incongruent trials). This binning procedure resulted in the following trial allocations: on average, the bin of fastest RTs consisted of 160 congruent (mean RT: $524 \mathrm{~ms}$ ) and 61 incongruent trials (mean RT: $532 \mathrm{~ms}$ ); the faster bin of 121 congruent (mean RT: $591 \mathrm{~ms}$ ) and 100 incongruent trials (mean RT: $595 \mathrm{~ms}$ ); the slower bin of 94 congruent (mean RT: $649 \mathrm{~ms}$ ) and 131 incongruent trials (mean RT: $651 \mathrm{~ms}$ ); and the slowest bin of 86 congruent (mean RT: $729 \mathrm{~ms}$ ) and 138 incongruent trials (mean RT: $734 \mathrm{~ms})$.

For each of the eight conditions, we then extracted theta-band ERSP values from the $200 \mathrm{~ms}$ time window ending at the mean trial-subset RT and subjected them to repeated-measures ANOVAs with the factors " $\mathrm{S}-\mathrm{R}$ congruency" (congruent, incongruent) and "Response speed" (fastest, faster, slower, slowest). This ANOVA on mean changes in theta $(4-7 \mathrm{~Hz})$ log power revealed significant main effects of "S-R congruency" and "Response speed." As shown in Figure $6 C$, weakest MFC theta bursts were elicited in trials with fastest RTs, with theta burst power gradually increasing as RTs became slower $\left(F_{(3,27)}=33.35, p<\right.$ $0.01)$. Independent of this response speed effect (interaction: $\left.F_{(3,27)}=0.14, p>0.94\right)$, stimuli requiring spatially incongruent responses induced stronger MFC theta power than stimuli with spatially congruent responses $\left(F_{(1,9)}=14.85, p<0.01\right)$. This pattern indicates that conflict- and RT-related processes affect mean MFC theta power independently of one another (compare Fig. 6D).

While the interaction between "S-R congruency" and "Response speed" was far from significance $(p>0.94)$, it remains possible that the use of only four response speed bins was insuf- ficient for the interaction to reach significance. For example, it may well be that variance becomes larger as RT increases, with a lot of important variance being lost when using RT quartiles. To control for this possibility, and to take the variance over all trials into account, we additionally computed within-subject correlations between MFC theta power and RTs and then compared (Pearson's linear) correlation coefficients between congruent and incongruent conditions (using paired $t$ tests). This analysis revealed the difference between congruent (mean correlation coefficient: 0.18 ) and incongruent trials (mean correlation coefficient: 0.17 ) to be far from significance ( $p>0.85$ ), confirming the previous observation of MFC theta power being modulated independently by conflict- and RT-related processes in the present task.

\section{Estimating relative contributions of conflict-related and - unrelated processes to MFC theta}

In the next step, we attempted to estimate the relative contributions of conflict-related versus -unrelated processes to the increase in MFC theta power, that is: do the former make a greater, a smaller, or an equal contribution compared with the latter?

First, to estimate the combined effects of both conflict-related and -unrelated processes, we calculated the mean magnitude of the MFC theta increase across trials (in the $200 \mathrm{~ms}$ preresponse window of the respective ERSPs) separately for the congruent and incongruent conditions. For each RT bin (quartile), we multiplied the theta power value by the number of trials contained in the trial bin. The products of all four bins were then summed and subsequently divided by the total number of (congruent and, respectively, incongruent) trials. The difference between the resulting congruent- and incongruent-trial theta power was taken to reflect the combined effects of conflict- and RT-related processes on MFC theta power (Fig. 7D, left). Averaged across both hands, the overall difference between congruent and incongruent trials was $0.22 \mu \mathrm{V}^{2}$ (paired $t$ test: $p<0.005$ ). Looking at response side separately, the difference was more pronounced and significant for right-hand trials $\left(0.28 \mu \mathrm{V}^{2} ; p<0.001\right)$ and approached significance for left-hand trials $\left(0.16 \mu \mathrm{V}^{2} ; p<0.06\right)$.

Second, to isolate the "conflict effect" on MFC theta bursts from conflict-unrelated processes, we estimated the mean magnitude of the MFC theta increase across the RT quartiles (separately for the congruent and incongruent conditions). In detail, we summed theta power across all four RT bins and subsequently divided the sum by 4 (the number of bins). The difference, obtained by subtracting the resulting congruent from incongruent 


\section{Medial Pre-frontal Cortex Cluster}

\section{A Single-trial Theta Power Sorted by RT}
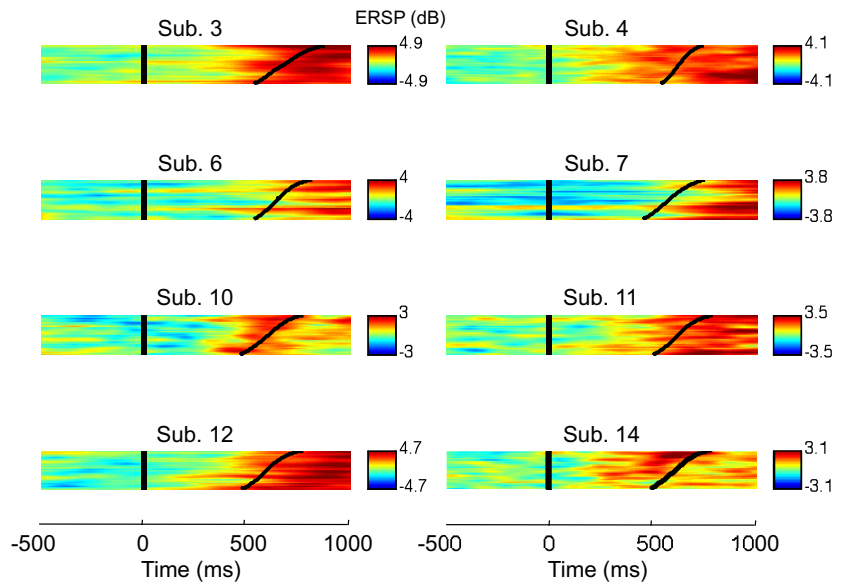

\section{Medial Frontal Cortex Cluster}

\section{Single-trial Theta Power Sorted by RT}

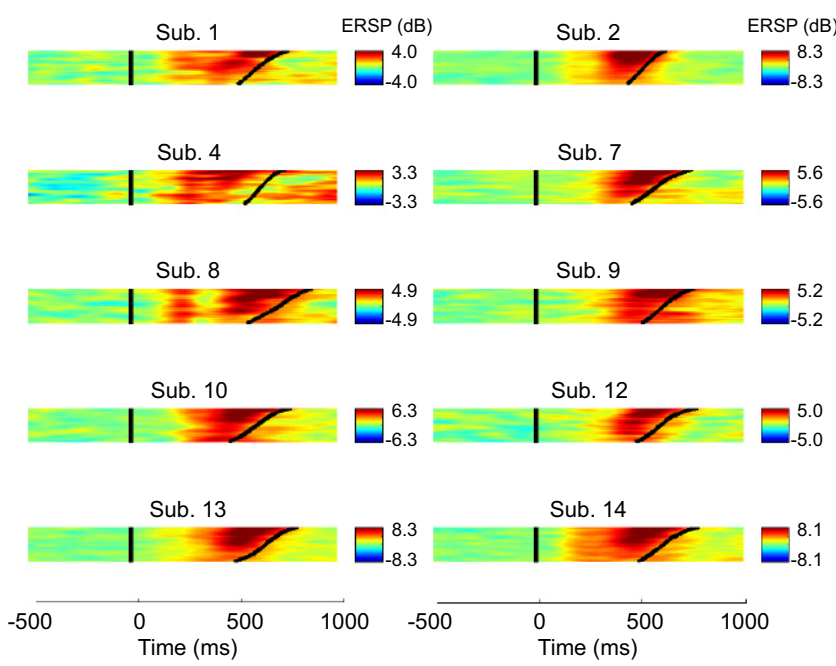

\section{B ERSP Analysis Grouped by RT}

$(\mathrm{dB})$
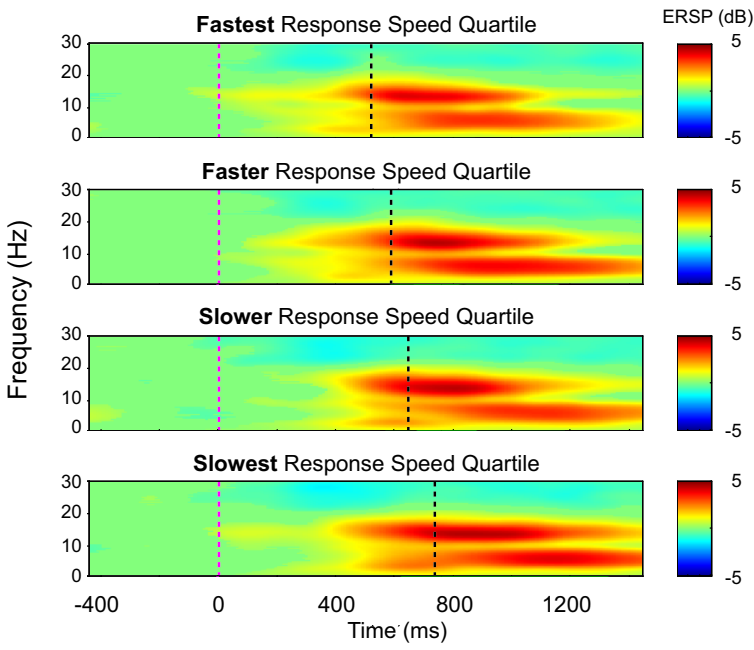

D ERSP Analysis Grouped by RT

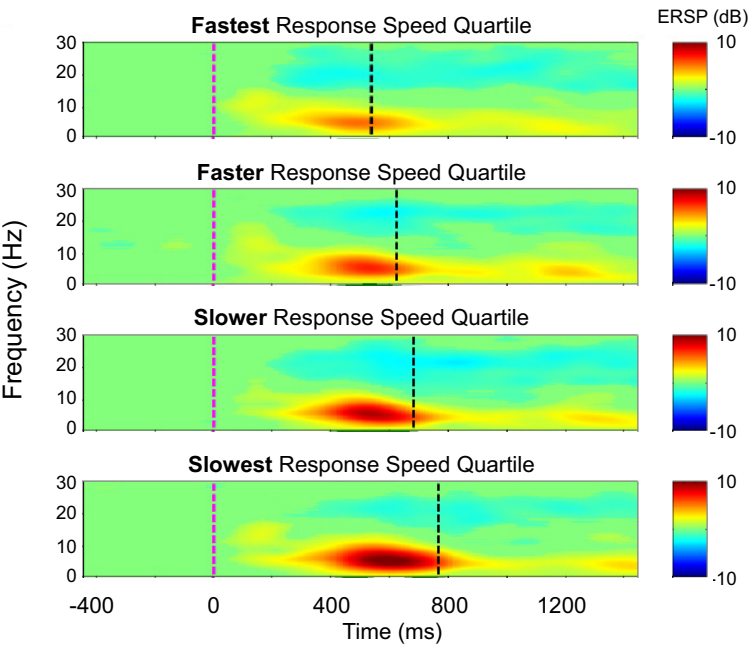

Figure 5. fm $\theta$ power changes across congruent and incongruent trials sorted by RT and synchronized to stimulus onsets (at time 0 ). $A$, Spectrographic images of all trials sorted by RT for each of the 8 participants contributing to the MPFC cluster. B, MPFC ERSPs for trials in four RT-sorted groups (fastest, faster, slower, slowest). C, Spectrographic images of all trials sorted by RT for each of the 10 participants contributing to the MFC cluster. Note the higher mean theta power before slower responses (top traces in each panel). D, MFC ERSPs for trials in four RT-sorted groups (very fast, fast, slow, very slow). Note, again, that the theta power increase is larger in slower RT trials.

theta power (Fig. 7D, middle), provides an estimate of the pure conflict-driven MFC theta increase. For both hands averaged, the (conflict-related) difference was significant (paired $t$ test: $p<$ $0.004)$ and amounted to $0.17 \mu \mathrm{V}^{2}$, that is, $76 \%$ of the combined effect. As before, the difference was marginally larger for righthand $\left(0.21 \mu \mathrm{V}^{2} ; p<0.001\right)$ than for left-hand trials $\left(0.14 \mu \mathrm{V}^{2}\right.$; $p<0.07)$.

Third, we estimated the contribution of "conflict-unrelated processes" to the MFC theta increase via averaging congruent and incongruent trials, thus effectively cancelling out (the contribution of) S-R conflicts. In detail, we calculated the theta power increase for each RT bin (separately for congruent and incongruent trials), taking the differential trial numbers per condition into account. That is, for each quartile, the theta power obtained (by averaging congruent and incongruent trials) was multiplied by the number of (congruent and, respectively, incongruent) trials contained in the respective bin. The products for all four bins were then summed up and subsequently divided by the total number of (congruent and incongruent) trials. As before, the difference, obtained by subtracting congruent from incongruent theta power (Fig. $7 D$, right), provides an estimate of the pure contribution of conflict-unrelated processes to the MFC theta power increases. Across both response hands, there was a significant difference (paired $t$ test: $p<0.01$ ) of $0.05 \mu \mathrm{V}^{2}$ (i.e., $24 \%$ of the combined effect). Mirroring the previous analyses, the difference was stronger and significant for right-hand trials $\left(0.07 \mu \mathrm{V}^{2}\right.$; 


\section{Medial Pre-frontal Cortex Theta}

A Response-Locked theta activity

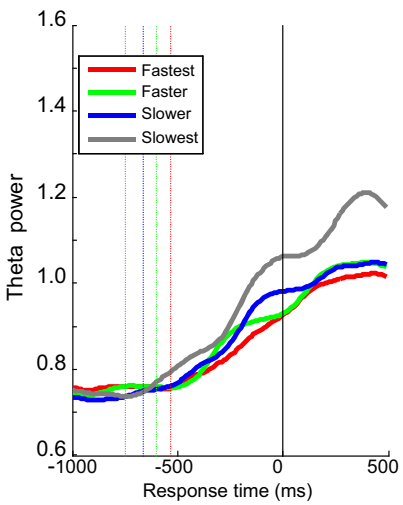

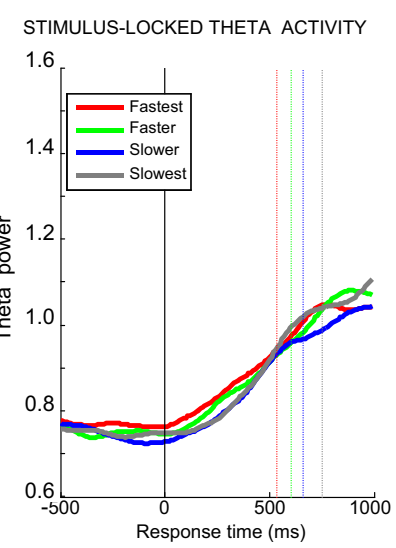

\section{Medial Frontal Cortex Theta}

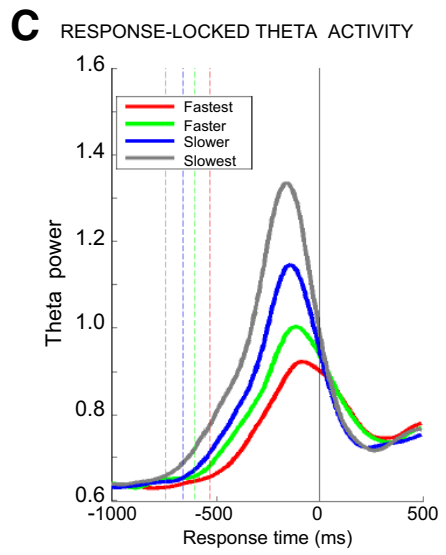

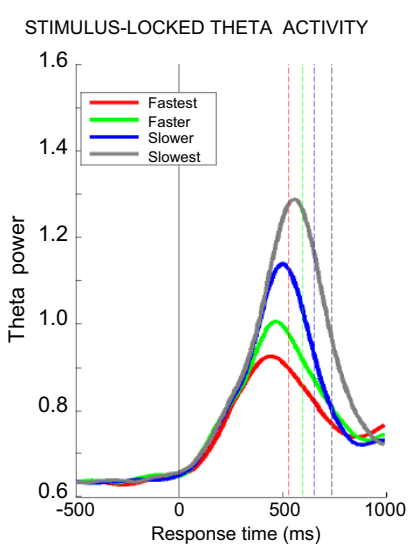
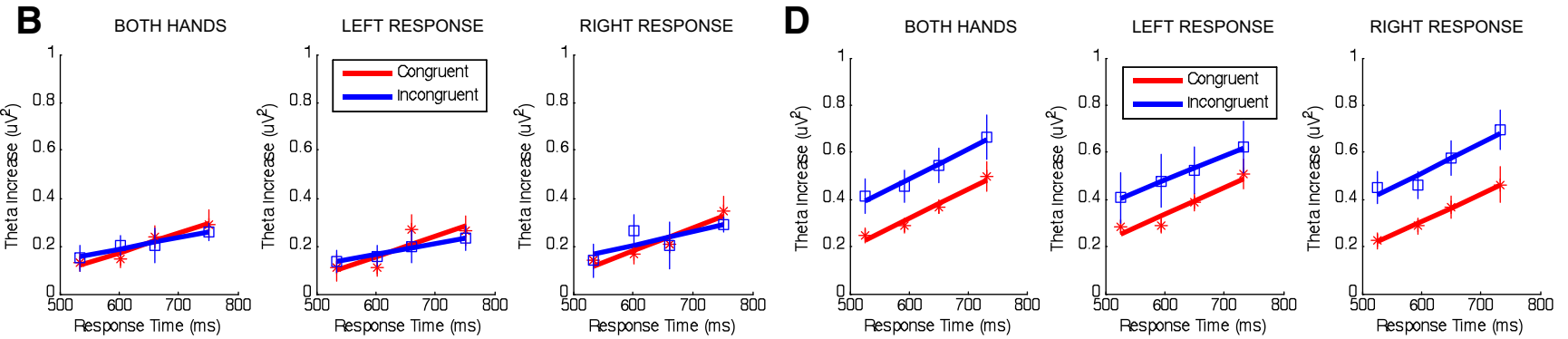

Figure 6. $\mathrm{fm} \theta$ activity separately for each response speed quartile (fastest, faster, slower, slowest). $\boldsymbol{A}$, RT quartile-dependent MPFC theta power synchronized to response (left) and stimulus onset (right). B, MPFC theta power separately for congruent (red) and incongruent trials (blue) as a function of RT quartile. C, RT quartile-dependent MFC theta power synchronized to response (left) and stimulus onset (right). D, MFC theta power separately for congruent (red) and incongruent trials (blue) as a function of RT quartile. Theta power was extracted from the $200 \mathrm{~ms}$ time window ending at the mean trial-subset RT, with theta increases estimated by subtracting mean baseline power in the ( $-1000 \mathrm{~ms}$ to $-750 \mathrm{~ms})$ time window before response onset.

$p<0.001)$ and approached significance level for left-hand trials $\left(0.02 \mu \mathrm{V}^{2} ; p<0.07\right)$.

\section{Response speed and MPFC theta}

Although the previous analyses had revealed that the present MPFC theta complex was elicited independently of S-R conflict, it cannot be ruled out that this complex indexes S-R conflicts for a subset of trials (e.g., in slower but not in faster RT quartiles), a pattern that might have remained hidden when performing the analyses for congruent and incongruent conditions averaged across all trials. To control for this possibility, we performed the same RT quartile-dependent analyses for the MPFC theta power, as (described above) for the MFC theta power. Stimulus-locked MPFC theta power time courses in all trials were first sorted by RT for each participant individually (Fig. 5A) and then divided into four quartile bins representing different response speed levels (Fig. 5B). Theta-band ERSP values from the $200 \mathrm{~ms}$ time window ending at the mean trial-subset RT, extracted separately for each of the eight conditions, were used for statistical comparisons. Of note, the different RT quartiles consisted of exactly the same (congruent and incongruent) trials as the MFC theta power analyses.

The repeated-measures ANOVA with the factors "S-R congruency" (congruent, incongruent) and "Response speed" (fastest, faster, slower, slowest) on MPFC theta $(4-7 \mathrm{~Hz}) \log$ power revealed the main effect of "Response speed" to be significant $\left(F_{(3,21)}=8.80, p<0.01\right)$, whereas the main effect of "S-R congruency" $\left(F_{(1,7)}=0.04, p>0.83\right)$ and the interaction $\left(F_{(3,21)}=\right.$ $0.97, p>0.42$ ) were nonsignificant. As depicted in Figure $6 B$, the response speed effect is due to generally increasing MPFC theta power for trials with slower relative to faster RTs, without an effect of or modulation by S-R congruency. As for the MFC analyses, we also computed within-subject correlations between MPFC theta power and RTs (for comparisons of correlation coefficients between congruent and incongruent conditions) to examine whether the nonsignificant interaction might be due to variance loss because of our RT binning procedure (see above). Supporting our previous findings, this analysis confirmed that RT-related processes modulated MPFC theta power independently of S-R congruence, as evidenced by statistically indifferent $(p>0.65)$ mean correlation coefficients for congruent $(0.08)$ and incongruent trials (0.07). Given that response speed modulated both MPFC and MFC theta power, we further examined whether the effect of RT on the two clusters correlate with one another. These analyses revealed a significant correlation for congruent trials $(p<0.05)$, but not for incongruent trials $(p>0.19)$, corroborating that conflict-unrelated effects in $\operatorname{fm} \theta$ power are not selective to the MFC complex.

\section{Quantifying the contribution of RT-related processes to MPFC theta}

Finally, we sought to quantify the contribution of conflict-unrelated processes to the MPFC theta bursts triggered in congruent and incongruent trials, and to assess whether the RT-related influence depends on (left vs right) response side. To this end, we performed the same analysis for the MPFC power as used for estimating the relative contributions of conflict-related and -unrelated processes to the MFC theta power (see above). 


\section{Medial Pre-frontal Cortex Theta}

A Both Hands
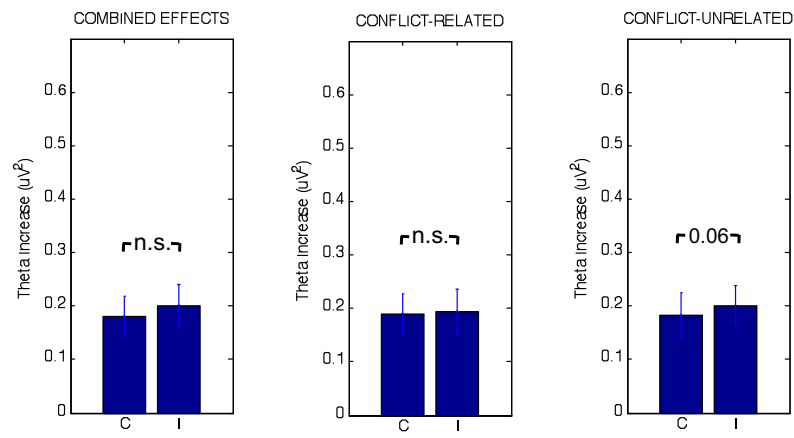

B Left-Hand Responses
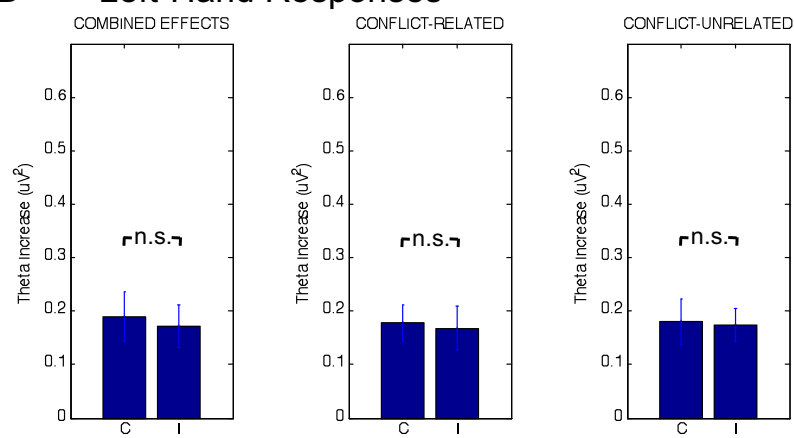

C Right-Hand Responses
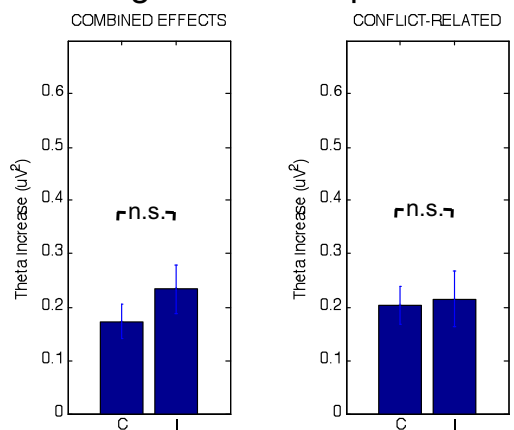

\section{Medial Frontal Cortex Theta}

\section{Both Hands}

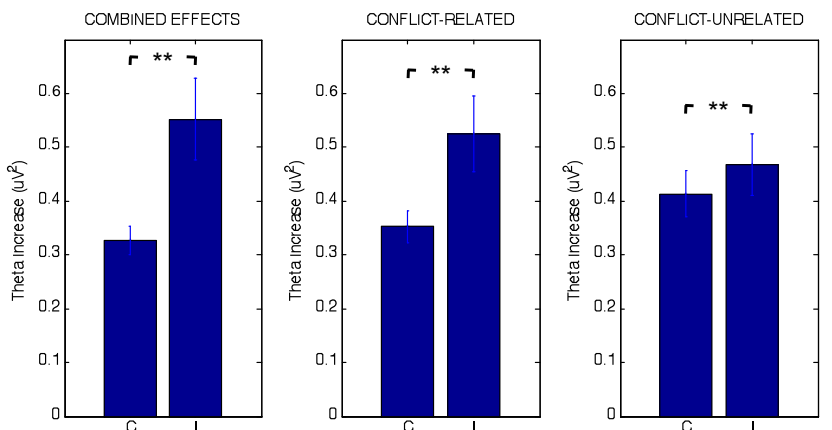

\section{E}
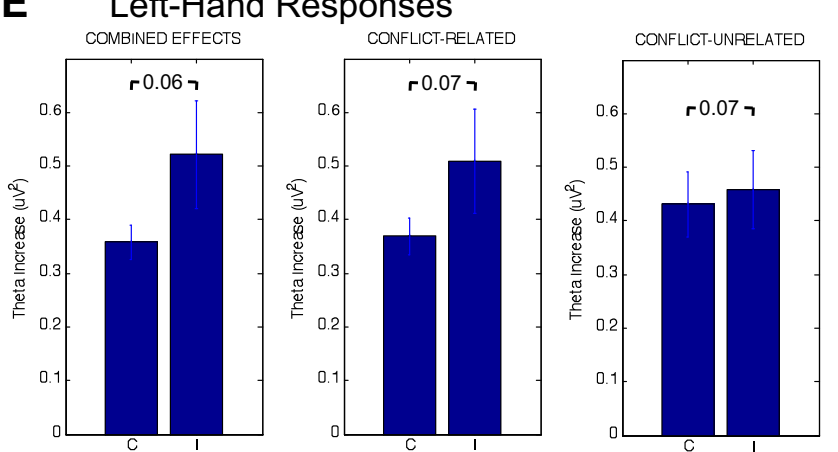

F Right-Hand Responses
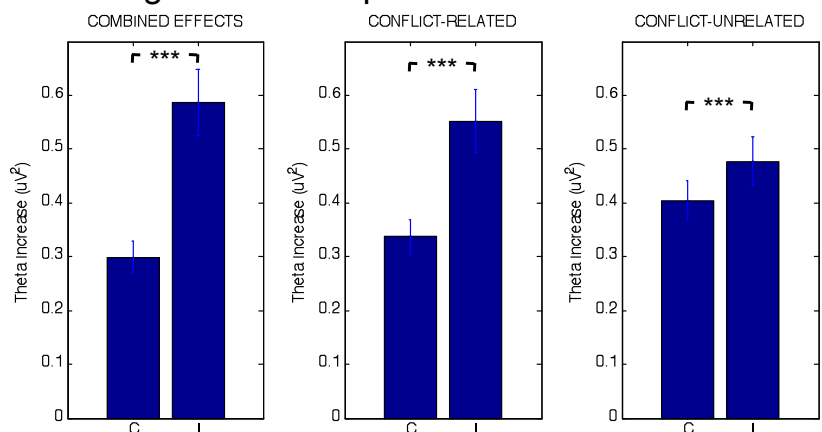

Figure 7. fm $\theta$ activity (averaging ERSP values in the $200 \mathrm{~ms}$ window preceding the motor response) separately for congruent (C) and incongruent (I) trials. $A$, MPFC theta averaged across hands $\boldsymbol{B}$, MPFC theta for left-hand responses. $\boldsymbol{C}$, MPFC theta for right-hand responses. $\boldsymbol{D}$, MFC theta averaged across hands. $\boldsymbol{E}$, MFC theta for left-hand responses. $\boldsymbol{F}$, MFC theta for right-hand responses. Each subfigure, Left, C-I differences reflecting the "combined effects" of conflict and RT-related processes. Middle, C-I differences reflecting the isolated conflict effects. Right, C-I differences reflecting the isolated effect of conflict-unrelated processes. Significant and nonsignificant differences between congruent and incongruent conditions are indicated by the respective $p$ values. ${ }^{* *} p<0.01$; ${ }^{* * *} p<0.001$.

For the conflict-unrelated influence to MPFC theta power, we found a significant difference between congruent and incongruent trials for right-hand $\left(0.05 \mu \mathrm{V}^{2}\right.$; paired $t$ test: $p<0.01$; Fig. $7 C)$, but not for left-hand $\left(-0.01 \mu \mathrm{V}^{2}\right.$; paired $t$ test: $p>0.73$; Fig. $7 B)$ responses. When averaged across hands, the difference between congruent and incongruent trials was only marginally significant (paired $t$ test: $p<0.06$ ), amounting to $0.02 \mu \mathrm{V}^{2}$. To provide a full picture of the present MPFC theta complex, we also estimated the contribution of putative conflict-related differences to MPFC theta power (using the RT quartile-dependent procedure as described above), and examined whether congruent and incongruent trials remained statistically different when computing the combined effects, which represent essentially the sum of conflict-unrelated and (putatively present) conflict-related differences across S-R conditions. Consistent with our previous findings, this analysis showed that MPFC theta bursts during congruent and incongruent trials were triggered independently of S-R conflict (all $p$ values: $>0.43$ ). Similarly, none of the comparisons reached statistical significance for the combined effects (all $p$ values: $>0.15$ ).

\section{Discussion}

In the current study, we set out to explore whether there are several theta generators in or near anterior cingulate cortex that jointly give rise to the scalp-recorded EEG spectral responses typically found in paradigms involving S-R conflicts (Nigbur et al., 2011; Cavanagh et al., 2012; van Driel et al., 2012). In particular, we aimed at identifying the cortical areas generating conflictinduced $\operatorname{fm} \theta$ complexes in a Simon-type manual reaching task to resolve the open issue whether multiple, conflict-related (detec- 
tion and adaptation) and conflict-unrelated processes (general RT slowing) can be linked to statistically independent $\operatorname{fm} \theta$ oscillations; or, alternatively, whether multiple processes can drive one-and-the-same $\operatorname{fm} \theta$ complex. At the behavioral level, our results replicated the pattern well known from the Simon task literature (Simon, 1969; Hommel, 1995): participants' RTs were slower for incongruent than for congruent trials, with the incongruency effect being reduced on trials that followed a conflict on the previous trial.

\section{Two independent $\operatorname{fm} \theta$ generators}

By means of ICA decomposition (Makeig et al., 1996), our EEG analyses identified two functionally distinct $\operatorname{fm} \theta$ patterns during target processing, both of which started $\sim 400$ ms after stimulus and exhibited a clear $\operatorname{fm} \theta$-related scalp distribution. Dipole source localization revealed that one $\operatorname{fm} \theta$ oscillation was triggered in (or near) the MFC, whereas the other originated from a more anterior region of medial cortex: the MPFC. The most important observation was, however, that only the former cluster reflected the noncorrespondence (i.e., the conflict) between $\mathrm{S}$ and R locations. In particular, MFC theta power was enhanced for incongruent relative to congruent trials, whereas no such difference was discernable for MPFC theta power. Moreover, MFC theta activity was modulated by trial-to-trial (conflict) history, with reduced MFC theta power triggered in incongruent trials when participants had processed a conflict on the trial before, and depended additionally on conflict-unrelated processes that were associated with RT slowing.

The finding that spatially incongruent S-R situations give rise to a stronger $\operatorname{fm} \theta$ response that is modulated by trial-to-trial history is in accord with recent studies that used classical (Cohen and Ridderinkhof, 2013; Gulbinaite et al., 2014) or diverse (cueing) versions of the Simon task (Cavanagh et al., 2012; van Driel et al., 2015). From all these studies, however, it remained unclear (1) whether this pattern originates from a mixture of multiple $\operatorname{fm} \theta$ sources in the MFC, and, if so, (2) whether they are all related to conflict detection and/or subject to trial-to-trial adaptation. Thus, to our knowledge, our findings provide the first demonstration that at least two classes of functionally independent $\operatorname{fm} \theta$ generators are simultaneously active during conflict processing in a Simon-type task. Critically, only one of the two produced larger theta responses in trials with S-R incongruency, providing strong electrophysiological support for the recent proposal that a single, spatially restricted microcircuit in the MFC is responsible for the detection and signaling of conflict (Cohen, 2014).

\section{Dissociating conflict from conflict-unrelated processes in MFC theta oscillations}

Our results yield important insights for a challenge that can be leveled against virtually all studies using RT paradigms to explore EEG oscillations, namely, that the change in the oscillatory pattern may be a direct correlate of a concurrent RT change. In this regard, it has been argued that the increase in theta activity for incongruent relative to congruent trials, rather than reflecting the $\mathrm{S}-\mathrm{R}$ conflict per se, may be an effect of increased RTs or more general, conflict-independent RT-slowing processes (Scherbaum and Dshemuchadse, 2013). Arguing against this view, opponents pointed out that this notion has limitations when taking neurobiological and psychological constraints into account (Cohen and Nigbur, 2013), favoring the view that $\operatorname{fm} \theta$ tracks the strength of response conflict and that RT can be taken as a behavioral index of such a conflict.
Here we show that conflict-related MFC theta bursts in a Simon-type task cannot be attributed to a single factor: MFC theta was larger in trials on which S-R locations differed and, independently of this conflict-related modulation, increased in trials with slower responses. This pattern is consistent with the compromise view that MFC theta increases in the present task are determined both by conflict-related and general RT-slowing processes. Specifically, processes not related to conflict contributed approximately one-fourth to the overall MFC theta bursts (averaged across both hands; Fig. 7D), with conflict-related processes contributing the "lion's share" (approximately three-fourths). Concerning the former, potential candidates for RT slowing processes that are not related to conflict include attentional resource allocation during visuo-motor processing (Makeig et al., 2004; Sauseng et al., 2007; Cravo et al., 2011), decision-making (Rushworth et al., 2004; Womelsdorf et al., 2010; Euston et al., 2012), or working memory-related processes (Gevins et al., 1997; Jensen and Tesche, 2002; Onton et al., 2005). However, to what degree each of these, or alternative, conflict-unrelated factors may have contributed to the present MFC theta power remains an open issue (to be resolved in future studies).

\section{Conflict-induced $\mathrm{fm} \theta$ complexes as a common neural substrate for cognitive control in response-override tasks?}

Finally, there has been a steadily growing interest in $\operatorname{fm} \theta$ and the idea that conflict-related characteristics of this brain response may reflect a unitary cognitive control mechanism for human conflict processing (Ridderinkhof et al., 2004; Nigbur et al., 2011; Cavanagh and Frank, 2014). For example, it has been proposed that non-phase-locked theta induced by conflicting task information modulates obligatory phase-locked theta responses evoked by perceptual and/or action events, resulting in the wellestablished pattern of conflict-related $\operatorname{fm} \theta$ increases (Cohen and Donner, 2013). Support for this notion derived from recent electrocortical findings from a particular class of conflict tasks that, as the Simon task, is characterized by a competition between the appropriate response demanded by the stimulus and an alternative, prepotent response that has to be overridden. Other examples of such response-override tasks include the Stroop task (Hanslmayr et al., 2008; Oehrn et al., 2014), the Eriksen flanker task (Cavanagh et al., 2009; Nigbur et al., 2012), and the response-priming task (Pastötter et al., 2010; Pastötter et al., 2013). Hanslmayr et al. (2008), for instance, observed stronger scalp $\mathrm{fm} \theta$ responses for incongruent relative to congruent stimuli in the Stroop task. Essentially the same pattern has been replicated for the Eriksen flanker task (Nigbur et al., 2012) and the response-priming task (Pastötter et al., 2013). Given these similarities, there is a general consensus that the same cognitive control process, indexed by conflict-induced $\operatorname{fm} \theta \operatorname{complexes,~may~}$ mediate interference detection and conflict monitoring across response-override tasks.

Although there is undoubtedly a remarkable overlap across various conflict paradigms ( $\mathrm{Lu}$ and Proctor, 1995) and beyond (Rushworth et al., 2007), it remains a point of contention whether conflict-related $\operatorname{fm} \theta$ increases reflect indeed the very same cognitive control mechanism. Put differently, if conflictinduced $\operatorname{fm} \theta$ complexes represent a unitary, task-independent process for detecting and resolving conflicts across responseoverride tasks, then one would predict that, regardless of the specific task at hand, this brain response should be (1) generated in exactly the same cortical region, and (2) similarly sensitive to intertrial (conflict) history. Closer inspection of the recent response-override task literature discloses, however, that these 
criteria are not fulfilled. First, it has been shown that, even though incongruent relative to congruent trial types give rise to a brief increase in theta EEG power with a clear focus over $\operatorname{fm} \theta$ areas in the Stroop, Simon, and response-priming tasks, their exact underlying neural sources vary. Whereas conflict-related $\operatorname{fm} \theta$ elicited in response-priming tasks originates from the left ACC, extending to the left pre-SMA (Pastötter et al., 2013), the sources generating conflict-related $\operatorname{fm} \theta$ in the Stroop task (Hanslmayr et al., 2008) and the present Simon-type task were localized, without any consistent lateralization to one cerebral hemisphere, in the dorsal ACC. Moreover, while conflict-related $\operatorname{fm} \theta$ power in both the response-priming task (Pastötter et al., 2013) and the present Simon-type task was influenced by conflicts on the previous trial, no such adaptation effects have been found for trialaveraged theta responses in the Erikson task (Cohen and Cavanagh, 2011).

Thus, despite striking similarities of $\operatorname{fm} \theta$ across various response-override tasks, there are also crucial differences that mitigate the hypothesis of conflict-related $\operatorname{fm} \theta$ as reflecting the very same cognitive control mechanism for resolving conflict. Notably, the pattern of task-dependent, conflict-related $\operatorname{fm} \theta$ increases provides electrocortical evidence for the view, put forward by Hommel (2011), that the Simon, Stroop, and Erikson effects should not be treated as representing the same (conflict) phenomena. As pointed out by Hommel (2011), the Simon effect can be traced back to the noncorrespondence between S-R locations. For the Erikson and Stroop effects, by contrast, the conflictinduced response slowing may have at least two sources: any cost for incongruent trials in these tasks may be due to the conflict between the two stimulus-related feature codes (e.g., blue vs red colors and, respectively, target vs flanker items), the conflict between the associated response codes, or a mixture of both. Together, our results fit well with the notion of task-dependent brain processes that resolve experienced S-S and S-R conflicts across different response-override tasks and which likely translate into task-dependent $\operatorname{fm} \theta$ characteristics.

\section{References}

Bell AJ, Sejnowski TJ (1995) An information-maximization approach to blind separation and blind deconvolution. Neural Comput 7:1129-1159. CrossRef Medline

Botvinick MM, Cohen JD, Carter CS (2004) Conflict monitoring and anterior cingulate cortex: an update. Trends Cogn Sci 8:539-546. CrossRef Medline

Buzsaki G (2006) Rhythms of the brain. Oxford: Oxford UP.

Cavanagh JF, Frank MJ (2014) Frontal theta as a mechanism for cognitive control. Trends Cogn Sci 18:414-421. CrossRef Medline

Cavanagh JF, Cohen MX, Allen JJ (2009) Prelude to and resolution of an error: EEG phase synchrony reveals cognitive control dynamics during action monitoring. J Neurosci 29:98-105. CrossRef Medline

Cavanagh JF, Zambrano-Vazquez L, Allen JJ (2012) Theta lingua franca: a common mid-frontal substrate for action monitoring processes. Psychophysiology 49:220-238. CrossRef Medline

Cohen MX (2014) A neural microcircuit for cognitive conflict detection and signaling. Trends Neurosci 37:480-490. CrossRef Medline

Cohen MX, Cavanagh JF (2011) Single-trial regression elucidates the role of prefrontal theta oscillations in response conflict. Front Psychol 2:30. CrossRef Medline

Cohen MX, Donner TH (2013) Midfrontal conflict-related theta-band power reflects neural oscillations that predict behavior. J Neurophysiol 110:2752-2763. CrossRef Medline

Cohen MX, Nigbur R (2013) Reply to "Higher response time increases theta energy, conflict increases response time." Clin Neurophysiol 124:1479-1481. CrossRef

Cohen MX, Ridderinkhof KR (2013) EEG source reconstruction reveals frontal-parietal dynamics of spatial conflict processing. PLoS One 8:e57293. CrossRef Medline
Cohen MX, Ridderinkhof KR, Haupt S, Elger CE, Fell J (2008) Medial frontal cortex and response conflict: evidence from human intracranial EEG and medial frontal cortex lesion. Brain Res 1238:127-142. CrossRef Medline

Cravo AM, Rohenkohl G, Wyart V, Nobre AC (2011) Endogenous modulation of low frequency oscillations by temporal expectations. J Neurophysiol 106:2964-2972. CrossRef Medline

Delorme A, Makeig S (2004) EEGLAB: an open source toolbox for analysis of single-trial EEG dynamics including independent component analysis. J Neurosci Methods 134:9-21. CrossRef Medline

Delorme A, Palmer J, Onton J, Oostenveld R, Makeig S (2012) Independent EEG sources are dipolar. PLoS One 7:e30135. CrossRef Medline

Egner T (2007) Congruency sequence effects and cognitive control. Cogn Affect Behav Neurosci 7:380-390. CrossRef Medline

Euston DR, Gruber AJ, McNaughton BL (2012) The role of medial prefrontal cortex in memory and decision making. Neuron 76:1057-1070. CrossRef Medline

Fuchs M, Kastner J, Wagner M, Hawes S, Ebersole JS (2002) A standardized boundary element method volume conductor model. Clin Neurophysiol 113:702-712. CrossRef Medline

Gevins A, Smith ME, McEvoy L, Yu D (1997) High-resolution EEG mapping of cortical activation related to working memory: effects of task difficulty, type of processing, and practice. Cereb Cortex 7:374-385. CrossRef Medline

Gramann K, Onton J, Riccobon D, Mueller HJ, Bardins S, Makeig S (2010) Human brain dynamics accompanying use of egocentric and allocentric reference frames during navigation. J Cogn Neurosci 22:2836-2849. CrossRef Medline

Gratton G, Coles MG, Donchin E (1992) Optimizing the use of information: strategic control of activation of responses. J Exp Psychol 121:480 506. CrossRef Medline

Gulbinaite R, van Rijn H, Cohen MX (2014) Fronto-parietal network oscillations reveal relationship between working memory capacity and cognitive control. Front Hum Neurosci 8:761. CrossRef Medline

Hanslmayr S, Pastötter B, Bäuml KH, Gruber S, Wimber M, Klimesch W (2008) The electrophysiological dynamics of interference during the Stroop task. J Cogn Neurosci 20:215-225. CrossRef Medline

Hommel B (1995) Stimulus-response compatibility and the Simon effect: toward an empirical clarification. J Exp Psychol 21:764

Hommel B (2011) The Simon effect as tool and heuristic. Acta Psychol (Amst) 136:189-202. CrossRef Medline

Hommel B, Proctor RW, Vu KP (2004) A feature-integration account of sequential effects in the Simon task. Psychol Res 68:1-17. CrossRef Medline

Ishii R, Shinosaki K, Ukai S, Inouye T, Ishihara T, Yoshimine T, Hirabuki N, Asada H, Kihara T, Robinson SE, Takeda M (1999) Medial prefrontal cortex generates frontal midline theta rhythm. Neuroreport 10:675-679. CrossRef Medline

Jensen O, Tesche CD (2002) Frontal theta activity in humans increases with memory load in a working memory task. Eur J Neurosci 15:1395-1399. CrossRef Medline

Kerns JG (2006) Anterior cingulate and prefrontal cortex activity in an FMRI study of trial-to-trial adjustments on the Simon task. Neuroimage 33:399-405. CrossRef Medline

Lee TW, Girolami M, Sejnowski TJ (1999) Independent component analysis using an extended infomax algorithm for mixed subgaussian and supergaussian sources. Neural Comput 11:417-441. CrossRef Medline

Lewicki MS, Sejnowski TJ (2000) Learning overcomplete representations. Neural Comput 12:337-365. CrossRef Medline

$\mathrm{LuCH}$, Proctor RW (1995) The influence of irrelevant location information on performance: a review of the Simon and spatial Stroop effects. Psychonom Bull Rev 2:174-207. CrossRef Medline

Makeig S (1993) Auditory event-related dynamics of the EEG spectrum and effects of exposure to tones. Electroencephalogr Clin Neurophysiol 86: 283-293. CrossRef Medline

Makeig S, Bell AJ, Jung TP, Sejnowski TJ (1996) Independent component analysis of electroencephalographic data. Adv Neural Information Proc Systems 145-151.

Makeig S, Westerfield M, Jung TP, Enghoff S, Townsend J, Courchesne E, Sejnowski TJ (2002) Dynamic brain sources of visual evoked responses. Science 295:690-694. CrossRef Medline

Makeig S, Delorme A, Westerfield M, Jung TP, Townsend J, Courchesne E, 
Sejnowski TJ (2004) Electroencephalographic brain dynamics following manually responded visual targets. PLoS Biol 2:e176. CrossRef Medline

Mayr U, Awh E, Laurey P (2003) Conflict adaptation effects in the absence of executive control. Nat Neurosci 6:450-452. CrossRef Medline

Mückschel M, Stock AK, Dippel G, Chmielewski W, Beste C (2016) Interacting sources of interference during sensorimotor integration processes. Neuroimage 125:342-349. CrossRef Medline

Nigbur R, IvANOVA G, Stürmer B (2011) Theta power as a marker for cognitive interference. Clin Neurophysiol 122:2185-2194. CrossRef Medline

Nigbur R, Cohen MX, Ridderinkhof KR, Stürmer B (2012) Theta dynamics reveal domain-specific control over stimulus and response conflict. J Cogn Neurosci 24:1264-1274. CrossRef Medline

Oehrn CR, Hanslmayr S, Fell J, Deuker L, Kremers NA, Do Lam AT, Elger CE, Axmacher N (2014) Neural communication patterns underlying conflict detection, resolution, and adaptation. J Neurosci 34:10438-10452. CrossRef Medline

Onton J, Delorme A, Makeig S (2005) Frontal midline EEG dynamics during working memory. Neuroimage 27:341-356. CrossRef Medline

Oostenveld R, Oostendorp TF (2002) Validating the boundary element method for forward and inverse EEG computations in the presence of a hole in the skull. Hum Brain Mapp 17:179-192. CrossRef Medline

Palmer JA, Kreutz-Delgado K, Makeig S (2006) Super-Gaussian mixture source model for ICA. In: International Conference on Independent Component Analysis and Signal Separation, pp 854-861. New York: Springer.

Palmer JA, Makeig S, Kreutz-Delgado K, Rao BD (2008) Newton method for the ICA mixture model. In: International conference on acoustics, speech and signal processing, pp 1805-1808. IEEE.

Pastötter B, Hanslmayr S, Bäuml KH (2010) Conflict processing in the anterior cingulate cortex constrains response priming. Neuroimage 50: 1599-1605. CrossRef Medline

Pastötter B, Dreisbach G, Bäuml KH (2013) Dynamic adjustments of cognitive control: oscillatory correlates of the conflict adaptation effect. J Cogn Neurosci 25:2167-2178. CrossRef Medline

Ridderinkhof KR, Ullsperger M, Crone EA, Nieuwenhuis S (2004) The role of the medial frontal cortex in cognitive control. Science 306:443-447. CrossRef Medline

Rushworth MF, Buckley MJ, Behrens TE, Walton ME, Bannerman DM (2007) Functional organization of the medial frontal cortex. Curr Opin Neurobiol 17:220-227. CrossRef Medline

Rushworth MF, Walton ME, Kennerley SW, Bannerman DM (2004) Action sets and decisions in the medial frontal cortex. Trends Cogn Sci 8:410417. CrossRef Medline

Sauseng P, Hoppe J, Klimesch W, Gerloff C, Hummel FC (2007) Dissociation of sustained attention from central executive functions: local activity and interregional connectivity in the theta range. Eur J Neurosci 25:587593. CrossRef Medline

Scherbaum S, Dshemuchadse M (2013) Higher response time increases theta energy, conflict increases response time. Clin Neurophysiol 124: 1477-1479. CrossRef Medline

Simon JR (1969) Reactions toward the source of stimulation. J Exp Psychol 81:174-176. CrossRef Medline

Simon JR, Small AM Jr (1969) Processing auditory information: interference from an irrelevant cue. J Appl Psychol 53:433-435. CrossRef Medline

Töllner T, Gramann K, Müller HJ, Kiss M, Eimer M (2008) Electrophysiological markers of visual dimension changes and response changes. J Exp Psychol Hum Percept Perform 34:531-542. CrossRef Medline

Töllner T, Müller HJ, Zehetleitner M (2012a) Top-down dimensional weight set determines the capture of visual attention: evidence from the PCN component. Cereb Cortex 22:1554-1563. CrossRef Medline

Töllner T, Rangelov D, Müller HJ (2012b) How the speed of motorresponse decisions, but not focal-attentional selection, differs as a function of task set and target prevalence. Proc Natl Acad Sci U S A 109: E1990-E1999. CrossRef Medline

Ullsperger M, Bylsma LM, Botvinick MM (2005) The conflict adaptation effect: it's not just priming. Cogn Affect Behav Neurosci 5:467-472. CrossRef Medline

Umiltà C, Nicoletti R (1992) An integrated model of the Simon effect. In: Analytic Approaches to Human Cognition (Alegria J, Holender D, Junca de Morais J, Radeau M, eds), pp 331-350. Oxford: North-Holland.

van Driel J, Ridderinkhof KR, Cohen MX (2012) Not all errors are alike: theta and alpha EEG dynamics relate to differences in error-processing dynamics. J Neurosci 32:16795-16806. CrossRef Medline

van Driel J, Swart JC, Egner T, Ridderinkhof KR, Cohen MX (2015) (No) time for control: frontal theta dynamics reveal the cost of temporally guided conflict anticipation. Cogn Affect Behav Neurosci 15:787-807. CrossRef Medline

Wallace RJ (1971) SR compatibility and the idea of a response code. J Exp Psychol 88:354-360. CrossRef Medline

Womelsdorf T, Vinck M, Leung LS, Everling S (2010) Selective thetasynchronization of choice-relevant information subserves goal-directed behavior. Front Hum Neurosci 4:210. CrossRef Medline 